\title{
Intrauterine Growth Restriction following Ligation of the Uterine Arteries Leads to More Severe Glomerulosclerosis after Mesangioproliferative Glomerulonephritis in the Offspring
}

\author{
Christian Plank $^{a} \quad$ Kai-Dietrich Nüsken ${ }^{a, d} \quad$ Carlos Menendez-Castro $^{a}$ \\ Andrea Hartner $^{a}$ Iris Östreicher ${ }^{a}$ Kerstin Amann ${ }^{b}$ Pia Baumann ${ }^{b}$ \\ Harm Peters ${ }^{c}$ Wolfgang Rascher ${ }^{a}$ Jörg Dötsch ${ }^{a, d}$
}

Departments of a Pediatrics and Adolescent Medicine and ${ }^{b}$ Renal Pathology, University of Erlangen-Nuremberg, Erlangen, and ${ }^{\mathrm{C}}$ Department of Nephrology, Center for Cardiovascular Research, Charité Universitätsmedizin Berlin, Charité Campus Mitte, Humboldt University Berlin, Berlin, and d Department of Pediatrics and Adolescent Medicine, University of Cologne, Cologne, Germany

\section{Key Words}

Intrauterine growth restriction - Uterine artery ligation - Small for gestational age - Thy-1.1 nephritis • Glomerulosclerosis $\cdot$ Collagens

\begin{abstract}
Background: Low birth weight is a risk factor for the development of a more severe course of secondary renal diseases. We tested the hypothesis that experimental mesangioproliferative glomerulonephritis (GN) shows an aggravated course in rats inflicted with experimental uteroplacental insufficiency during gestation. Methods: Intrauterine growth restriction (IUGR) was induced by ligation of both uterine arteries on day 19 in pregnant Wistar rat dams. GN was induced in male offspring at the age of 9 weeks by intravenous injection of an anti-Thy-1.1 antibody. At day 14 of GN, kidneys were taken and analyzed for glomerular morphometry, markers of inflammation, glomerulosclerosis and tubulointerstitial fibrosis. Results: Despite a similar extent of mesangiolysis, former IUGR animals presented with a higher level of glomerulosclerosis and increased deposition of glomerular collagens I and IV compared to nephritic control animals.
\end{abstract}

Arterial blood pressure, renal function, and proteinuria after 14 days of GN were not influenced by former IUGR. Conclusion: Ligation of the uterine arteries in the rat leads to more pronounced sclerotic changes in the glomerulus in the offspring suffering from acute GN. This finding supports the hypothesis that former IUGR increases the susceptibility for a more severe course of secondary renal diseases.

Copyright $\odot 2010$ S. Karger AG, Basel

\section{Introduction}

Low birth weight is a risk factor for the development of a more severe course of glomerular disease. Retrospective clinical studies have demonstrated that children with idiopathic nephrotic syndrome who were born small for gestational age (SGA) have a higher incidence of relapses, steroid dependency and steroid resistance than children with a history of normal birth weight [1-3]. Former SGA children with idiopathic nephrotic syndrome also have a higher need for additional immunosuppressive therapy, such as alkylating agents and cyclosporin A [4]. In pediatric IgA nephropathy, data reported in the 1990s indi-

\section{KARGER}

Fax +41613061234 E-Mail karger@karger.ch www.karger.com (c) 2010 S. Karger AG, Basel

$0250-8095 / 10 / 0324-0287 \$ 26.00 / 0$

Accessible online at:

www.karger.com/ajn
Christian Plank, MD

Kinder- und Jugendklinik, Universitätsklinikum Erlangen

Loschgestrasse 15, DE-91054 Erlangen (Germany)

Tel. +49 9131853 3118, Fax +49 91318533113

E-Mail christian.plank@uk-erlangen.de 
cate that up to $30 \%$ of the patients eventually develop endstage renal failure [5]. A retrospective study of 62 children with IgA nephropathy reported a 3-fold higher number of sclerotic glomeruli among children who were born SGA as compared to those without a history of low birth weight [6].

An experimental rat model of acute, reversible mesangioproliferative glomerulonephritis (GN) mimicking some of the aspects of IgA nephropathy is the Thy-1.1 nephritis induced by application of an antibody targeting the Thy-1.1 antigen on mesangial cells. In this context, our group showed a more severe course of Thy-1.1 nephritis in rats with intrauterine growth restriction (IUGR) induced by low protein diet to pregnant dams [7]. Low protein diet throughout pregnancy is the most frequently used model for the induction of IUGR and subsequent renal disease of the offspring [8]. However, the most common cause of human IUGR in the industrial world is placental insufficiency, which may not be represented by the low protein model [9]. The IUGR model in rats, which is much closer to human placental insufficiency, is ligation of the uterine arteries [10]. Therefore, it was the objective of the present study to examine the impact of uteroplacental insufficiency on the course of acute mesangioproliferative $\mathrm{GN}$ in the offspring.

\section{Materials and Methods}

\section{Animal Procedures}

All procedures performed on animals were done in accordance with the guidelines of the American Physiological Society and were approved by the local government authorities (Regierung von Mittelfranken, AZ \#621-2531.31-08/03 and AZ \#6212531.31-14/05). Time-mated female Wistar rats (HsdCpb:WU) in their first pregnancy were purchased from Harlan-Winkelmann (Borchen, Germany) and housed individually from day 13 postcoitum under air-conditioning providing a temperature of $22 \pm$ $2{ }^{\circ} \mathrm{C}$, constant relative humidity of $55 \%$, and a 12 -hour dark/light cycle. The animals were allowed unlimited access to standard rat chow and tap water. On day 19 postcoitum, the pregnant dams were anesthetized by an injection of $5 \mathrm{mg} / \mathrm{kg}$ midazolam and 100 $\mathrm{mg} / \mathrm{kg}$ ketamine. After midline laparotomy, both uterine horns were pulled out of the abdomen until exposed completely, and the living fetuses were counted. Then, either a ligation of both uterine arteries (LIG) at the most caudal point accessible was carried out with 6-0 prolene (Ethicon, Norderstedt, Germany), or the suture material was not fixed but removed under identical anesthetic and surgical procedures (SOP). All animals carried 3-9 living fetuses per uterine horn (5-7 in the LIG group). The uterus was then placed back into the abdominal cavity which was closed with a 4-0 vicryl suture (Ethicon). All surgeries were performed between 11:00 and 14:00 $\mathrm{h}$. The rats started drinking and taking food within $4-8 \mathrm{~h}$ and recovered fully before the beginning of the dark cycle at 19:00 h. All pregnant rats delivered spontaneously on day 21 or 22 postcoitum within a time frame of $12 \mathrm{~h}$. On the first day of life, 13 male LIG pups (6 litters) and 13 male SOP pups (4 litters) were chosen according to their birth weight (smallest 13 males available in the LIG litters; heaviest 13 males available in the SOP litters). Our selection criteria are based on the finding that only LIG fetuses in the caudal position (near the ligation) show growth restriction and should be compared with SOP fetuses in the caudal position, which are most often the heaviest pups of the respective litter [11]. The selected pups were transferred to untreated foster mothers, whose own pups had been killed, and remained with them until weaning on postnatal day 23. Each foster mother nursed 6 pups to assure uniformity of the litter size and optimal access to milk during nursing [12]. After weaning, the animals received standard chow.

At the age of 9 weeks, animals were randomly divided into 4 groups for this study with 1-2 animals from the same mother per group. Anti-Thy-1.1 mesangioproliferative GN was induced by a single intravenous injection of $1 \mathrm{mg} / \mathrm{kg}$ body weight monoclonal anti-Thy-1.1 antibody [13] into the tail vein in light ether anesthesia as described before [14]. Controls received saline only. Animals were sacrificed 14 days after GN induction. Groups are indicated as LIG+GN $(n=7), \operatorname{SOP}+\mathrm{GN}(\mathrm{n}=6), \mathrm{LIG}(\mathrm{n}=7)$, SOP $(n=6)$.

\section{Physiological Parameters}

Twenty-four hours before sacrifice, animals were housed in individual metabolic cages to collect urine for quantification. Blood samples were obtained at sacrifice. At the day of sacrifice starting at $08.00 \mathrm{~h}$, all animals were instrumented with femoral catheters for intra-arterial blood pressure measurements. Catheters were implanted in the right femoral artery under $5 \mathrm{mg} / \mathrm{kg}$ midazolam and $100 \mathrm{mg} / \mathrm{kg}$ ketamine anesthesia intraperitoneally. Catheters were tunneled subcutaneously in order to prevent the rats from interfering with the catheters [15]. At the end of the operation, animals were antagonized with $0.2 \mathrm{ml}$ atipamezole $(5 \mathrm{mg} /$ $\mathrm{ml}$; Antisedan ${ }^{\circledR}$, Pfizer $\mathrm{GmbH}$ ) and woke up within 3-5 min. Two hours after anesthesia, mean arterial blood pressure was recorded on a polygraph (Hellige, Freiburg, Germany) in conscious rats for $30 \mathrm{~min}$ in the animals' home cages. Protein and creatinine in serum and urine samples were analyzed with the automatic analyzer Integra 800 (Roche Diagnostics, Mannheim, Germany). Endogenous creatinine clearance was calculated.

\section{Tissue Preparation}

After arterial blood pressure measurement the experiment was terminated by retrograde perfusion via the abdominal aorta in deep anesthesia $(5 \mathrm{mg} / \mathrm{kg}$ midazolam and $100 \mathrm{mg} / \mathrm{kg} \mathrm{ke}$ tamine). First, the left kidney was taken out and portions of the cortex were immediately snap-frozen in liquid nitrogen for mRNA analysis. Another portion of renal tissue was fixed in methyl-Carnoy solution (60\% methanol, 30\% chloroform and $10 \%$ glacial acetic acid). After removing the left kidney, the organs of the animals were perfusion fixed with $3 \%$ glutaraldehyde for morphometric and stereological measurements as described in detail elsewhere [16-18]. Then the right kidney was taken out, weighed and dissected in a plane perpendicular to the interpolar axis, yielding slices of $1 \mathrm{~mm}$ width. Ten small pieces of each kidney were selected by area-weighted sampling for Epon-Araldite embedding [16-18]. The remaining tissue slices were embedded 
Table 1. Designed primer pairs and TaqMan probes used in this study

\begin{tabular}{|c|c|c|}
\hline MCP-1 & $\begin{array}{l}\text { forward } \\
\text { reverse } \\
\text { probe }\end{array}$ & $\begin{array}{l}\text { 5'-CCTCCACCACTATGCAGGTCTC-3' } \\
\text { 5'-GCACGTGGATGCTACAGGC-3' } \\
\text { 5'(FAM)-TCACGCTTCTGGGCCTGTTGTTCA-(TAMRA)3' }\end{array}$ \\
\hline OPN & $\begin{array}{l}\text { forward } \\
\text { reverse } \\
\text { probe }\end{array}$ & $\begin{array}{l}\text { 5'-AAAGTGGCTGAGTTTGGCAG-3' } \\
\text { 5'-AAGTGGCTACAGCATCTGAGTGT-3' } \\
\text { 5'(FAM)-TCAGAGGAGAAGGCGCATTACAGCA-(TAMRA)3' }\end{array}$ \\
\hline PAI-1 & $\begin{array}{l}\text { forward } \\
\text { reverse } \\
\text { probe }\end{array}$ & $\begin{array}{l}\text { 5'-TCCGCCATCACCAACATTTT-3' } \\
5^{\prime} \text {-GTCAGTCATGCCCAGCTTCTC-3' } \\
\text { 5'(FAM)-CCGCCTCCTCATCCTGCCTAAGTTCTCT-(TAMRA)3' }\end{array}$ \\
\hline TGF- $\beta_{1}$ & $\begin{array}{l}\text { forward } \\
\text { reverse } \\
\text { probe }\end{array}$ & $\begin{array}{l}\text { 5'-CACCCGCGTGCTAATGGT-3' } \\
5^{\prime} \text {-GGCACTGCTTCCCGAATG-3' } \\
\text { 5'(FAM)-ACCGCAACAACGCAATCTATGACA-(TAMRA)3' }\end{array}$ \\
\hline GAPDH & $\begin{array}{l}\text { forward } \\
\text { reverse } \\
\text { probe }\end{array}$ & $\begin{array}{l}\text { 5'-ACGGGAAACCCATCACCAT-3' } \\
\text { 5'-CCAGCATCACCCCATTTGA-3' } \\
\text { 5'(FAM)-TTCCAGGAGCGAGATCCCGTCAAG-(TAMRA) 3' }\end{array}$ \\
\hline PBGD & $\begin{array}{l}\text { forward } \\
\text { reverse } \\
\text { probe }\end{array}$ & $\begin{array}{l}\text { 5'-AGACCATGCAGGCCACCA-3' } \\
\text { 5'-CAACCAACTGTGGGTCATCCT-3' } \\
\text { 5'(FAM)-AGGTCCCTGTTCAGCAAGAAGATGGTCC-(TAMRA)3' }\end{array}$ \\
\hline$\beta$-Actin & $\begin{array}{l}\text { forward } \\
\text { reverse } \\
\text { probe }\end{array}$ & $\begin{array}{l}\text { 5' -TGAGCTGCCTGACGGTCAG-3' } \\
\text { 5'-TGCCACAGGATTCCATACCC-3' } \\
\text { 5'(FAM)-CACTATCGGCAATGAGCGGTTCCG-(TAMRA)3' }\end{array}$ \\
\hline Collagen $\mathrm{I}^{1}$ & $\begin{array}{l}\text { forward } \\
\text { reverse }\end{array}$ & $\begin{array}{l}\text { 5'-GACGCAGAAGTCATAGGAGTC-3' } \\
5^{\prime} \text {-GGAAGTCCAGGCTGTCCAG-3' }\end{array}$ \\
\hline Collagen III $^{1}$ & $\begin{array}{l}\text { forward } \\
\text { reverse }\end{array}$ & $\begin{array}{l}5^{\prime} \text {-ATATCAAACACGCAAGGC-3' } \\
5^{\prime} \text {-GATTAAAGCAAGAGGAACAC-3' }\end{array}$ \\
\hline
\end{tabular}

${ }^{1}$ Collagen I and III were detected by SYBR Green analysis.

in paraffin, $2-\mu \mathrm{m}$ sections were taken and stained with hematoxylin and eosin (HE) and periodic acid-Schiff (PAS). Using area-weighted sampling, 5 of the resin blocks were randomly selected from which semithin sections $(0.8 \mu \mathrm{m})$ were prepared and stained with methylene blue and basic fuchsin. Subsequently, the paraffin and semithin sections were investigated by morphometry and stereology [19] in a blinded fashion.

\section{RNA Extraction and Real-Time PCR}

RNA was extracted from the renal cortex using TRIzol reagent (Invitrogen, Paisley, UK) according to the manufacturer's instructions. Quantitative real-time RT-PCR analysis was performed as described previously [20] for osteopontin (OPN), monocyte chemoattractant protein 1 , plasminogen activator inhibitor 1 (PAI-1) and transforming growth factor- $\beta_{1}$ (TGF- $\left.\beta_{1}\right)$. Collagen I and III mRNA expression was quantified using the SYBR Green method in a BioRad iQ5 I-Cycler with the IQTM SYBR-Green ${ }^{\odot}$ Supermix (both Bio-Rad Laboratories, Hercules, Calif., USA). In all probes the relative amount of the specific mRNA was normalized with respect to porphobilinogen-desaminase (PBGD). The results were confirmed by normalization on other 'housekeeping genes' like $\beta$-actin or glyceraldehyde-3phosphate dehydrogenase (GAPDH). Primer pairs and TaqMan probes used are listed in table 1 . Unless otherwise indicated, the oligonucleotides for each gene investigated were designed by the use of Primer Express software (PerkinElmer, Foster City, Calif., USA) using uniform selection parameters that allowed for the application of standard cycle conditions.

\section{Kidney Histology}

The degree of mesangial matrix expansion and sclerosis within the glomerular tuft as an index of progression was determined on PAS-stained paraffin sections using a scoring system (glomerulosclerosis index, GSI) as described before [21]. Using light microscopy at a magnification of $\times 400$, the glomerular score of each animal was derived as the mean of 100 randomly sampled glomeruli. The severity of glomerulosclerosis was expressed on an arbitrary scale from 0 to 4 . The glomerular score for individual glomeruli was: grade 0 , normal glomerulus; grade 1, presence of mesangial expansion/thickening of the basement membrane; grade $2, \mathrm{mild} /$ moderate segmental hyalinosis/sclerosis involving less than $50 \%$ of the glomerular tuft; grade 3, diffuse glomerular 
hyalinosis/sclerosis involving more than $50 \%$ of the tuft; grade 4 , diffuse glomerulosclerosis with total tuft obliteration and collapse. The resulting index in each animal was expressed as a mean of all scores obtained. Crescent formation (in \%) was evaluated on PAS-stained paraffin sections at a magnification of $\times 400$ as the mean of 100 randomly sampled glomeruli.

To determine the extent of the formation of microaneurysms, capillary widening was scored on 100 randomly sampled glomeruli using PAS-stained sections at a magnification of $\times 400$. A semiquantitative scoring system (microaneurysm index) was applied with a score from 0 to 4 [21]: score 0 , no capillary widening in the glomerular tuft; score 1, capillary widening involving up to $25 \%$ of the glomerular tuft; score 2, capillary widening of 25-50\%; score 3, capillary widening of 50-75\%; score 4, capillary widening involving more than $75 \%$ of the glomerular tuft. The resulting index in each animal was expressed as a mean of all scores obtained.

Tubulointerstitial damage, i.e. tubular atrophy, tubular dilatation, interstitial fibrosis and interstitial inflammation, was assessed on PAS-stained paraffin sections at a magnification of $\times 100$ using a semiquantitative scoring system (tubulointerstitial lesion score) $[17,18]$. For determination of the tubulointerstitial lesion score, 10 fields per kidney were randomly sampled and graded as follows: grade 0 , no change; grade 1 , lesions involving less than $25 \%$ of the area; grade 2 , lesions affecting $25-50 \%$; grade 3 , lesions involving more than $50 \%$, and grade 4 involving (almost) the entire area.

Scoring was carried out by an investigator unaware of the experimental group to which each kidney belonged.

Glomerular geometry was assessed by point counting (100point eyepiece, Integrationsplatte II; Zeiss Co., Oberkochen, Germany) on paraffin sections (HE and PAS stain, light microscopy, various magnifications) as follows: area (AA) and volume density $(\mathrm{VV})$ of the renal cortex and medulla as well as the number of glomeruli per area (NA) were measured using a Zeiss eyepiece (Integrationsplatte II, Zeiss Co.) and the point-counting method $\left(\mathrm{P}_{\mathrm{P}}=\mathrm{A}_{\mathrm{A}}=\mathrm{V}_{\mathrm{V}}\right)$ at a magnification of $\times 400$ on HE sections [16-18]. In addition, volume density $\left(\mathrm{V}_{\mathrm{V}}\right)$ of glomeruli and area density of glomerular tuft $\left(\mathrm{A}_{\mathrm{AT}}\right)$ were also measured. The total area of the glomerular tuft was then determined as $\mathrm{A}_{\mathrm{T}}=\mathrm{A}_{\mathrm{AT}} \times \mathrm{A}_{\text {cortex }}$. In addition, the number of glomeruli per area $\left(\mathrm{N}_{\mathrm{A}}\right)$ was counted at a magnification of $\times 100$. The glomerular number per area $\left(\mathrm{N}_{\mathrm{A}}\right)$ was then corrected for tissue shrinkage. The number of glomeruli per volume $\left(\mathrm{N}_{\mathrm{V}}\right)$ and the volume density $\left(\mathrm{V}_{\mathrm{V}}\right)$ of glomeruli was calculated using the formula: $\mathrm{N}_{\mathrm{V}}=\mathrm{k} / \beta \times \mathrm{N}_{\mathrm{A}}{ }^{1.5 /} \mathrm{V}_{\mathrm{V}}{ }^{0.5}$ with $\mathrm{k}=1$ and $\beta=1.382$. Total cortex volume $\left(\mathrm{V}_{\text {cortex }}\right)$ was derived from kidney mass divided by the specific weight of the kidney $\left(1.04 \mathrm{~g} / \mathrm{cm}^{3}\right)$ times the volume density of the cortex. The total number of glomeruli was derived from the total volume of the renal cortex and the number of glomeruli per cortex volume: $\mathrm{N}_{\text {glom }}=\mathrm{N}_{\mathrm{V}} \times \mathrm{V}_{\text {Cortex }}$. The mean glomerular volume was then determined according to $\mathrm{v}=\mathrm{k} / \beta \times \mathrm{AT}^{1.5}$, with $\mathrm{k}=1.1$ and $\beta=1.382[16-18]$.

\section{Immunohistochemistry}

After overnight fixation in methyl-Carnoy solution, tissues were dehydrated by bathing in increasing concentrations of methanol, followed by $100 \%$ isopropanol. After embedding in paraffin, 3- $\mu \mathrm{m}$ sections were cut with a Leitz SM $2000 \mathrm{R}$ microtome (Leica Instruments, Nussloch, Germany). After deparaffinization, endogenous peroxidase activity was blocked with $3 \% \mathrm{H}_{2} \mathrm{O}_{2}$ in meth- anol for $20 \mathrm{~min}$ at room temperature. Glomerular and interstitial collagen I was detected by a rabbit polyclonal antibody (Biogenesis, Poole, UK) at a dilution of 1:1,000. A goat polyclonal antibody to collagen IV (Southern Biotechnology Associates, Birmingham, Ala., USA) was used at a dilution of 1:500. A mouse monoclonal antibody detecting proliferating cells (PCNA) was purchased from Dako (Hamburg, Germany) and used at a dilution of 1:50. The mouse monoclonal antibody to macrophages (ED-1) was from Serotec (Biozol, Eching, Germany) and diluted $1: 250$.

Immunohistochemistry was performed in deparaffinized sections of methyl-Carnoy fixed kidneys, using an avidin horseradish peroxidase detection system (Vector Laboratories, Burlingame, Calif., USA) as described before [22]. As a negative control, we used equimolar concentrations of preimmune rabbit or mouse immunoglobulin G. Each slide was counterstained with hematoxylin.

\section{Analysis of Data}

Proliferating cells (PCNA-positive cells) and macrophages (ED-1-positive cells) were counted in 100 glomeruli and expressed as positive cells per glomerular cross section. To evaluate glomerular collagen I and collagen IV, computer-based integration of stained areas was performed in 20 randomly selected glomeruli per kidney section (Metaview; Visitron Systems, Puchheim, Germany) in a blinded fashion. The average area staining positive for collagen I and collagen IV per glomerular cross section was calculated as a percentage of glomerular cross section [23].

Tubulointerstitial collagen I and collagen IV content and ED1-positive cells were counted at a $\times 400$ magnification using the point-counting method and a 121-point eyepiece (Integrationsplatte II, Zeiss Co.) in a blinded fashion. The results are expressed as the mean of 20 randomly selected non-overlapping fields.

The results of the real-time PCR studies were calculated based on the $\Delta \Delta \mathrm{Ct}$ - method as described in detail previously [24] and expressed as fold induction of mRNA expression compared to the SOP animal group. Messenger RNA expression in SOP animals was defined as 1.0-fold induction.

One-way analysis of variance (ANOVA) was used to test for significance. In the case of $\mathrm{p}<0.05$, posthoc Bonferroni tests were calculated to test significant differences between LIG vs. SOP, LIG-GN vs. SOP-GN, SOP vs. SOP-GN, and LIG vs. LIG-GN. A $p$ value $<0.05$ was considered significant. The procedures were carried out using the GraphPad Prism software (GraphPad Software, San Diego, Calif., USA). In order to analyze the influence of the independent factors uterine artery ligation (LIG) and induction of GN, we applied two-way analysis of variance (two-way ANOVA) for selected items. This test was calculated by PASW Statistics, Release 18 (SPSS Inc., Chicago, Ill., USA).

\section{Results}

\section{Physiological Parameters}

Uterine artery ligation in the pregnant dams led to a significant reduction of birth weights of their offspring (fig. 1a). At weaning (day 23 of life), rat offspring of the LIG group still had significantly lower weights than off- 
Fig. 1. Birth weights (a), body weights at weaning (b), and body weights at day 64 of life (c) at the time of induction of GN. LIG = Rat offspring after ligation of the uterine arteries, SOP $=$ sham operation. Data are means \pm SEM. ${ }^{*} \mathrm{p}<0.05 ;{ }^{* *} \mathrm{p}<$ $0.01 ;{ }^{* * *} \mathrm{p}<0.001, \mathrm{~ns}=$ not significant.

Fig. 2. Microaneurysm formation (a) and glomerular macrophage infiltration (b) in rats after ligation of the uterine arteries (LIG) or sham operation (SOP) with or without induction of GN. Data are means \pm SEM. ${ }^{*} \mathrm{p}<0.05 ;{ }^{* *} \mathrm{p}<0.01 ;{ }^{* * *} \mathrm{p}<$ $0.001, \mathrm{~ns}=$ not significant.
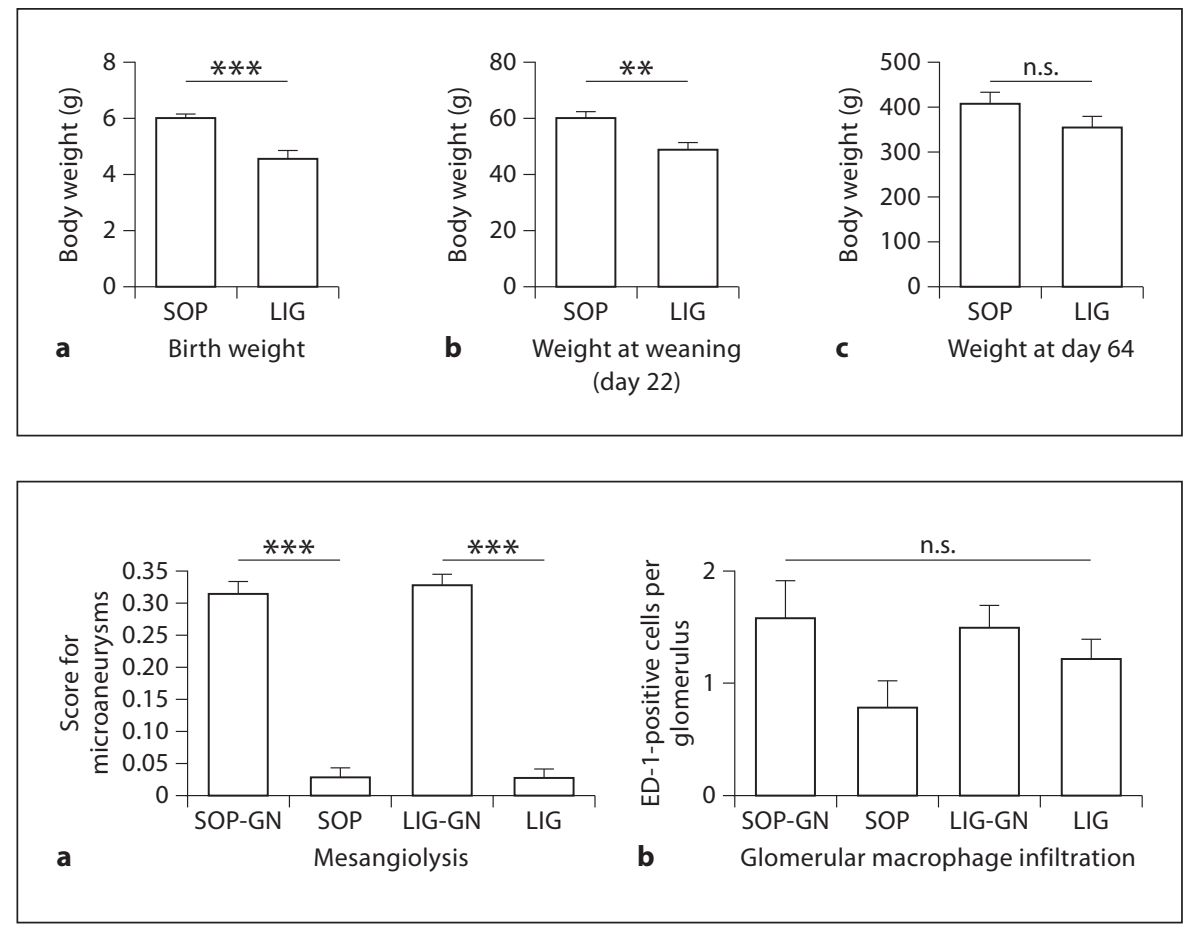

spring of the SOP group (fig. 1b). Catch-up growth was observed in LIG animals leading to body weights comparable to the body weights of the SOP control group at day 64 of life at the time when Thy-1.1 GN was induced (fig. 1c). Relative kidney and heart weights were not different between SOP and LIG groups (table 2). Induction of GN did not influence relative kidney or heart weights (table 2). Intra-arterial blood pressure recordings revealed no differences in mean arterial blood pressure levels of SOP and LIG rats regardless of whether GN was induced or not (table 2). Protein excretion was significantly higher after induction of GN without any differences observed between SOP and LIG groups (table 2). Plasma creatinine and creatinine clearance were similar in all groups investigated (table 2). The number of glomeruli was reduced in LIG compared to SOP groups, with a trend to further reduction caused by GN (table 2). In contrast, no significant differences in glomerular volume between SOP and LIG groups were detected, while induction of GN led to an increase in glomerular volume in both groups (table 2).

\section{Mesangiolysis and Inflammation}

Administration of the anti-Thy-1.1 antibody leads to a complement-dependent lysis of mesangial cells. Evaluation of mesangiolysis was done using a score for micro- aneurysms. Mesangiolysis was induced in both groups which had received the anti-Thy-1.1 antibody, without any differences between SOP and LIG groups (fig. 2a). Moreover, no differences were detected either in glomerular or tubulointerstitial macrophage infiltration (as assessed by immunohistochemistry for ED-1) between SOP and LIG groups (fig. 2b; table 3). Infiltration of macrophages in the glomerulus tended to be somewhat higher in the nephritic groups compared to controls, while tubulointerstitial infiltration was significantly increased in the nephritic LIG group and tended to be increased in the SOP group (fig. 2b; table 3). Real-time PCR analysis of renal cortical RNA for the two chemokines macrophage chemoattractant protein-1 (MCP-1) and OPN did not reveal any differences between SOP and LIG groups (table 3). GN led to an upregulation of OPN mRNA expression, while MCP-1 mRNA expression was not different in nephritic and control renal tissue 2 weeks after induction of GN (table 3).

\section{Fibrosis}

Glomerulosclerosis as assessed by a sclerosis score was increased after induction of GN with a significant difference between SOP-GN and LIG-GN groups; glomerulosclerosis was most severe in the LIG-GN group (fig. 3a). This finding was confirmed by morphometric evaluation 
Table 2. Physiological and stereological data from rats after LIG or SOP with or without induction of GN

\begin{tabular}{lccrc}
\hline Group & SOP $(\mathrm{n}=6)$ & SOP-GN $(\mathrm{n}=6)$ & LIG $(\mathrm{n}=7)$ & LIG-GN $(\mathrm{n}=7)$ \\
\hline Relative heart weight, mg/g b.w. & $4.90 \pm 0.16$ & $4.83 \pm 0.19$ & $5.10 \pm 0.10$ & $5.23 \pm 0.31$ \\
Mean arterial pressure, mm Hg & $11.4 \pm 4.19$ & $121.5 \pm 5.91$ & $104.4 \pm 1.70$ & $119.8 \pm 6.81$ \\
Relative kidney weight, mg/g b.w. & $3.95 \pm 0.06$ & $4.22 \pm 0.23$ & $4.00 \pm 0.16$ & $4.36 \pm 0.23$ \\
Number of glomeruli/kidney & $52,930 \pm 2,967$ & $45,601 \pm 2,528$ & $42,185 \pm 1,710^{\#}$ & $40,822 \pm 1,466$ \\
Mean glomerular volume, $\times 10^{3} \mu \mathrm{m}^{3}$ & $1,427 \pm 145$ & $2,124 \pm 336$ & $1,404 \pm 135$ & $2,085 \pm 257$ \\
Protein excretion, $\mathrm{mg} / 24 \mathrm{~h} / 100 \mathrm{~g} \mathrm{b.w.}$ & $5.52 \pm 0.65$ & $20.50 \pm 5.19^{*}$ & $6.21 \pm 1.67$ & $16.44 \pm 3.91^{*}$ \\
Plasma creatinine, $\mathrm{mg} / \mathrm{dl}$ & $0.288 \pm 0.022$ & $0.317 \pm 0.021$ & $0.260 \pm 0.023$ & $0.276 \pm 0.017$ \\
Creatinine clearance, $\mathrm{ml} / \mathrm{h} / 100 \mathrm{~g}$ b.w. & $50.97 \pm 12.26$ & $39.32 \pm 1.48$ & $43.55 \pm 5.77$ & $42.94 \pm 2.75$ \\
\hline
\end{tabular}

${ }^{*} \mathrm{p}<0.05$ vs. respective non-nephritic control group; ${ }^{\#} \mathrm{p}<0.05$ vs. SOP. Data are means \pm SEM.

Table 3. Markers of renal inflammation and fibrosis in rats after LIG or SOP with or without induction of GN

\begin{tabular}{|c|c|c|c|c|}
\hline Group & $\begin{array}{l}\text { SOP } \\
(n=6)\end{array}$ & $\begin{array}{l}\text { SOP-GN } \\
(n=6)\end{array}$ & $\begin{array}{l}\mathrm{LIG} \\
(\mathrm{n}=7)\end{array}$ & $\begin{array}{l}\text { LIG-GN } \\
(n=7)\end{array}$ \\
\hline Glomerular crescents (\% positive glomeruli) & $2.08 \pm 0.38$ & $8.33 \pm 1.96$ & $1.98 \pm 0.49$ & $12.67 \pm 2.52^{\#, *}$ \\
\hline Interstitial collagen I ( $\%$ positive stain per cortical view) & $1.26 \pm 0.07$ & $4.38 \pm 0.24^{*}$ & $2.07 \pm 0.12$ & $5.96 \pm 0.52^{*, \S}$ \\
\hline Interstitial collagen IV (\% positive stain per cortical view) & $3.13 \pm 0.20$ & $6.34 \pm 0.90^{*}$ & $3.43 \pm 0.27$ & $7.75 \pm 0.65^{*}$ \\
\hline Interstitial macrophages (ED-1-positive cells per cortical view) & $2.01 \pm 0.71$ & $6.63 \pm 1.24$ & $3.02 \pm 0.61$ & $7.82 \pm 1.66^{\#, *}$ \\
\hline MCP-1 expression (fold induction) & $1.00 \pm 0.34$ & $0.76 \pm 0.34$ & $0.85 \pm 0.22$ & $1.56 \pm 0.37$ \\
\hline OPN expression (fold induction) & $1.00 \pm 0.20$ & $16.89 \pm 6.92^{*}$ & $1.70 \pm 0.67$ & $11.17 \pm 2.31^{*}$ \\
\hline Collagen I expression (fold induction) & $1.00 \pm 0.19$ & $1.87 \pm 0.35$ & $1.15 \pm 0.23$ & $2.46 \pm 0.33^{*}$ \\
\hline Collagen III expression (fold induction) & $1.00 \pm 0.10$ & $1.00 \pm 0.31$ & $0.75 \pm 0.43$ & $2.42 \pm 0.42^{*, \S}$ \\
\hline TGF- $\beta_{1}$ expression (fold induction) & $1.00 \pm 0.33$ & $1.72 \pm 0.66$ & $0.65 \pm 0.34$ & $0.41 \pm 0.28$ \\
\hline PAI-1 expression (fold induction) & $1.00 \pm 0.26$ & $1.31 \pm 0.46$ & $1.06 \pm 0.35$ & $0.91 \pm 0.22$ \\
\hline
\end{tabular}

${ }^{*} \mathrm{p}<0.05$ vs. respective non-nephritic control group; ${ }^{\#} \mathrm{p}<0.05$ vs. SOP; ${ }^{\S} \mathrm{p}<0.05$ vs. SOP-GN. Data are means \pm SEM.

of glomerular collagen deposition. Collagen I and collagen IV deposition was most prominent in the glomeruli of LIG-GN animals (fig. 3b, c). Glomerular crescent formation, on the other hand, was more often observed in nephritic kidneys, at least in the LIG group, without any changes observed in the LIG-GN group compared to SOP-GN (table 3). Tubulointerstitial deposition of collagens I and IV was also clearly increased after induction of GN. The tubulointerstitial deposition of collagen I was significantly different in the LIG-GN group compared to SOP-GN, while collagen IV was not different between SOP and LIG groups (table 3). The evaluation of the renal cortical mRNA expression levels of collagens I and III revealed that the expression of collagen I was increased after induction of GN in the LIG group, but not in the SOP group. The expression of collagen III was increased in the LIG-GN group compared to its respective non-ne- phritic control, but also compared to SOP-GN (table 3). Additionally, the expression levels of two profibrotic factors were investigated; both TGF- $\beta_{1}$ and PAI-1 expression levels were comparable in all four groups investigated (table 3). The mRNA expression levels of all other modulators of extracellular matrix deposition and accumulation investigated, i.e. matrix metalloproteinases 2 and 9 as well as the tissue inhibitors of metalloproteinases (TIMP1 and -2) were comparable in the SOP and LIG groups (data not shown).

Testing by two-way ANOVA confirmed that both factors, LIG as well as induction of GN, led to more glomerulosclerosis and extracelluar matrix deposition, and that there was a significant interaction between both factors. However, mesangiolysis as a marker of initial glomerular damage in this model was not influenced by LIG (table 4). 
Fig. 3. GSI with sample pictures (a), deposition of glomerular collagen I (b), and deposition of glomerular collagen IV (c) in rats after ligation of the uterine arteries (LIG) or sham operation (SOP) with or without induction of GN. Data are means \pm SEM. ${ }^{*} \mathrm{p}<0.05 ;{ }^{* *} \mathrm{p}<0.01{ }^{* * *} \mathrm{p}<$ 0.001 .

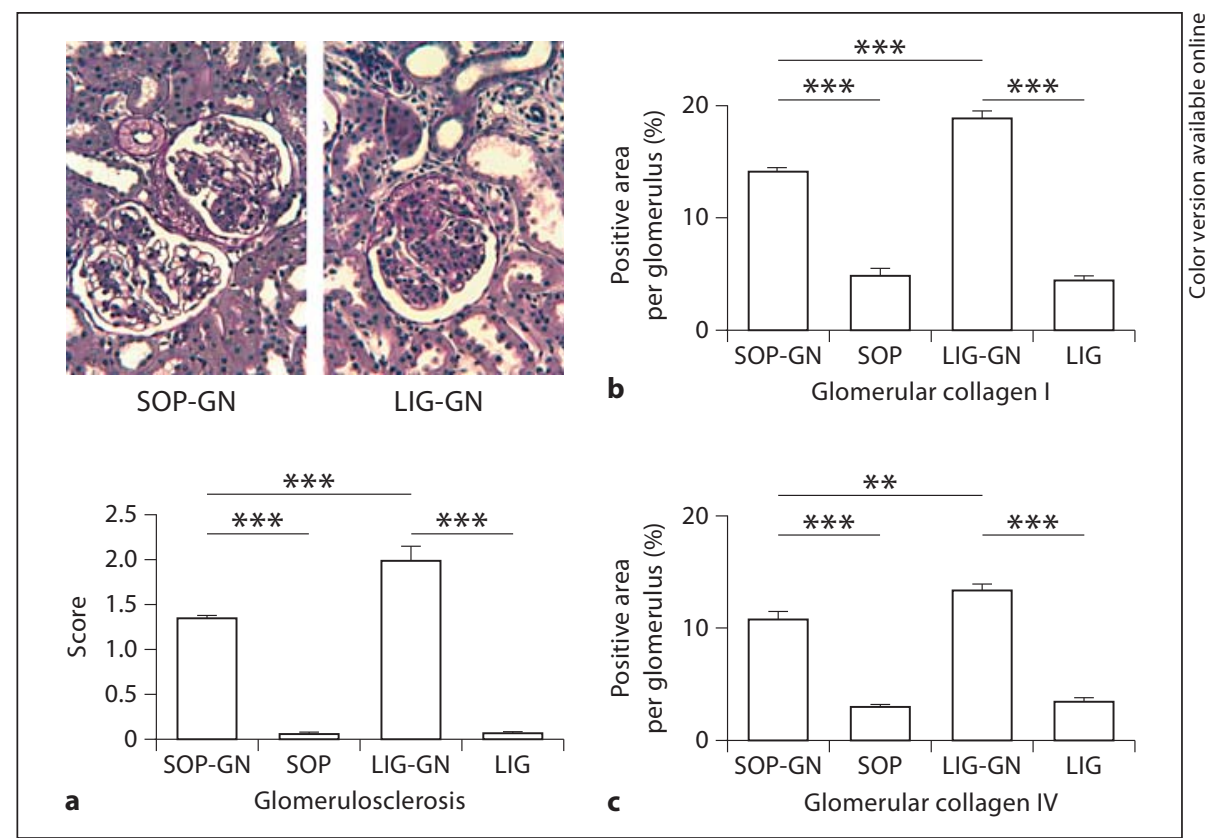

Table 4. $\mathrm{p}$ values from two-way ANOVA

\begin{tabular}{lcccc}
\hline & $\begin{array}{l}\text { Mesangiolysis } \\
\text { index }\end{array}$ & GSI & Glomerular & $\begin{array}{l}\text { Glomerular } \\
\text { collagen I } \\
\text { collagen IV }\end{array}$ \\
\hline p GN & $<0.001$ & $<0.001$ & $<0.001$ & $<0.001$ \\
p LIG & 0.651 & 0.001 & $<0.001$ & 0.003 \\
p LIG-GN & 0.368 & 0.002 & $<0.001$ & 0.005 \\
\hline
\end{tabular}

\section{Discussion}

The present study shows that IUGR inflicted in rats by experimental uteroplacental insufficiency leads to a higher degree of glomerulosclerosis after the induction of acute mesangioproliferative GN. This notion is further underlined by a higher deposition of collagens I and IV in glomeruli of the kidneys of IUGR animals. This is in accordance with results from a low protein nutrition-induced IUGR model [7]. In this former study, IUGR in the offspring was induced by low protein feeding ( $8 \%$ protein content) to pregnant Wistar dams mimicking maternal protein malnutrition. Injection of anti-Thy-1.1 antibody in the male offspring at the age of 8 weeks led to mesangioproliferative GN. In this transient disease model, reparation is almost accomplished on day 14 of GN [25], but in former IUGR animals mRNA expression of inflamma- tory markers like monocyte chemoattractant protein 1 , OPN or tumor necrosis factor $\alpha$ was still induced. Moreover, glomerulosclerosis and glomerular collagen I and IV deposition were more prominent than in control animals at day 14 [7].

In general, these findings support the 'first-hit-second-hit' hypothesis [26], proposing that secondary renal disease is aggravated as a consequence of unfavorable fetal conditions and low birth weight. In various renal diseases, like membranous nephropathy in adults [27], IgA nephropathy in children [6], idiopathic nephrotic syndrome in children $[3,4]$, renal damage after urinary tract infection [28] and diabetic nephropathy $[29,30]$, an association between low birth weight as a marker for an unfavorable intrauterine milieu and a later aggravated course of renal disease was described. In another experimental study, infusion of advanced glycation end-products in former IUGR rats increased renal mRNA expression of profibrotic cytokines and procollagen III [31]. Altogether, this proves a causal relationship between IUGR and an aggravated course of secondary renal diseases.

An important aspect in the development of renal lesions and hypertension after IUGR is nephron number. As proposed by Brenner et al. [32], a low nephron number is a risk factor for the development of hypertension and renal insufficiency later in life. Reduced nephron number is a common feature of various animal models of IUGR [33]. Thus, our data showing a mean reduction of the 
nephron number by $20 \%$ goes in line with the work of other groups [34]. Nephron deficit alone may be a progression factor for renal inflammation as shown by a chronic progressive course of disease in rats after antiThy-1.1 injection and consecutive uninephrectomy [35].

However, there may be differences in the renal outcome depending on the cause of IUGR. A direct comparison of the present data from animals after uterine artery ligation and our previous data on animals from a low protein IUGR model [7] is not possible, because different antibodies (from Antibody Solutions, Palo Alto, Calif., USA, in the previous study, from own preparations in the present study) and no direct control groups were used. But the time points of GN induction, duration of $\mathrm{GN}$, as well as the methods of analysis were comparable. Therefore, some features were obviously different and noteworthy to be mentioned. For example, there is no difference in clinical parameters such as proteinuria, arterial blood pressure, plasma creatinine or creatinine clearance between nephritic offspring from dams with uteroplacental insufficiency and sham operation. This is in contrast to our findings in the offspring of rats fed a low protein diet, where a significantly higher protein excretion was observed compared to controls [7]. In our hands, both models showed nephron reduction without hypertension, but in the protein restriction model there was a tendency to lower nephron number in the intervention group (mean reduction rate $26 \%$ ) compared to the uterine artery ligation model (mean nephron reduction 20\%). Furthermore, in our previous study, animals after low protein feeding revealed higher renal expression of early profibrotic and proinflammatory cytokines, like TGF- $\beta$ or MCP-1 as a marker of early renal damage [7], which was not seen in the present study. Commonly, low nephron number is linked to glomerular hypertrophy $[36,37]$. Hypertrophy might result in an increase of mechanical strain of the podocytes and subsequently in detachment and loss of podocytes, leading to a more severe renal damage, including proteinuria [38] when a second hit such as acute experimental GN is inflicted. In our experiments, hypertrophy of glomeruli is solely a feature of the kidneys of rats with IUGR induced by a maternal low protein diet [8]. While mean glomerular volume is increased in IUGR rats after maternal low protein diet compared to controls after maternal normal protein diet [7], this difference is not found between IUGR rats after uteroplacental insufficiency and sham-operated control animals. This might also explain in part why glomerular inflammation, detected by macrophage infiltration and expression of proinflammatory chemokines, is not different be- tween nephritic animals after uteroplacental insufficiency and sham-operated controls. In humans, increased glomerular size is associated with poorer renal function [39]. Nevertheless, the lack of glomerular hypertrophy in our animals after uterine artery ligation may be due to the young age at sacrifice compared to the work of others showing nephron reduction, glomerular hypertrophy and signs of renal damage, like proteinuria, at the age of 18 months in animals after uterine artery ligation [34, 40]. Another consideration might be that the injected anti-Thy-1.1 antibody directed against the Thy-1.1 antigen on the mesangial cell surface might be of lower efficiency in animals after uteroplacental insufficiency. However, we do not have any evidence to support this notion since the extent of mesangiolysis does not differ between animals with IUGR after uteroplacental insufficiency and sham-operated controls as shown in figure 2a and table 4 . Also, the induction of IUGR as evidenced by a lower birth weight in comparison to control animals was effective and comparable to the model of maternal low protein diet [7].

Finally, one has to be aware of the fact that not only ligation of the uterine arteries but also sham operation per se leads to a certain degree of IUGR bearing at least some of the features of the metabolic phenotype seen in the offspring after uteroplacental insufficiency [10].

In conclusion, the present study shows that the model of IUGR after uteroplacental insufficiency leads to a higher susceptibility of the offspring to develop a more severe course of acute experimental GN. This is in keeping with our previous findings in the IUGR model of maternal low protein diet [7]. However, the extent of renal damage inflicted by the different models of IUGR may differ. To answer this question, further studies in both models under equal conditions would be needed. Which of the models is closer to the human situation cannot be answered easily, however, since IUGR is a multifactorial process, the proof of certain principles in various models might be recommended.

\section{Acknowledgments}

We gratefully acknowledge the expert technical assistance of Sebastian Schrüfer, Julia Dobner, Jessica Heinze, Christine Pfeiffer, Miriam Reutelshöfer and Monika Klewer. We thank Dr. Manfred Rauh for the analysis of serum and urine samples.

This study was supported by a grant from the Deutsche Forschungsgemeinschaft, Bonn, Germany (SFB 423, Project A2 to A.H., Project Z2 to K.A., and B13 to C.P. and J.D.). 


\section{References}

1 Sheu JN, Chen JH: Minimal change nephrotic syndrome in children with intrauterine growth retardation. Am J Kidney Dis 2001; 37:909-914.

2 Zidar N, Avgustin Cavic M, Kenda RB, Ferluga D: Unfavorable course of minimal change nephrotic syndrome in children with intrauterine growth retardation. Kidney Int 1998;54:1320-1323.

3 Plank C, Östreicher I, Dittrich K, Waldherr $\mathrm{R}$, Voigt M, Amann K, Rascher W, Dotsch J: Low birth weight, but not postnatal weight gain, aggravates the course of nephrotic syndrome. Pediatr Nephrol 2007;22:1881-1889.

4 Teeninga N, Schreuder MF, Bokenkamp A, Delemarre-van de Waal HA, van Wijk JA: Influence of low birth weight on minimal change nephrotic syndrome in children, including a meta-analysis. Nephrol Dial Transplant 2008;23:1615-1620.

5 Goldstein AR, White RH, Akuse R, Chantler C: Long-term follow-up of childhood Henoch-Schönlein nephritis. Lancet 1992;339: 280-282.

6 Zidar N, Cavic MA, Kenda RB, Koselj M, Ferluga D: Effect of intrauterine growth retardation on the clinical course and prognosis of IgA glomerulonephritis in children. Nephron 1998;79:28-32.

7 Plank C, Östreicher I, Hartner A, Marek I, Struwe FG, Amann K, Hilgers KF, Rascher W, Dötsch J: Intrauterine growth retardation aggravates the course of acute mesangioproliferative glomerulonephritis in the rat. Kidney Int 2006;70:1974-1982.

8 Woods LL, Ingelfinger JR, Nyengaard JR, Rasch R: Maternal protein restriction suppresses the newborn renin-angiotensin system and programs adult hypertension in rats. Pediatr Res 2001;49:460-467.

9 Dötsch J, Plank C, Amann K, Ingelfinger J: The implications of fetal programming of glomerular number and renal function. J Mol Med 2009;87:841-848.

10 Nüsken KD, Dötsch J, Rauh M, Rascher W, Schneider H: Uteroplacental insufficiency after bilateral uterine artery ligation in the rat: Impact on postnatal glucose and lipid metabolism and evidence for metabolic programming of the offspring by sham operation. Endocrinology 2008;149:1056-1063.

11 Nüsken KD, Warnecke C, Hilgers KF, Schneider H: Intrauterine growth after uterine artery ligation in rats: dependence on the fetal position in the uterine horn and need for prenatal marking of the animals. J Hypertens 2007;25:247-248.

12 Wlodek ME, Mibus A, Tan A, Siebel AL, Owens JA, Moritz KM: Normal lactational environment restores nephron endowment and prevents hypertension after placental restriction in the rat. J Am Soc Nephrol 2007; 18:1688-1696.

13 Peters H, Border WA, Noble NA: Targeting TGF- $\beta$ overexpression: maximizing the antifibrotic actions of angiotensin II blockade in anti-Thy-1 glomerulonephritis. Nephrol Dial Transplant 1999;14 Suppl 4:22-23.
14 Plank C, Hartner A, Klanke B, Geissler B, Porst M, Amann K, Hilgers KF, Rascher W, Dötsch J: Adrenomedullin reduces mesangial cell number and glomerular inflammation in experimental mesangioproliferative glomerulonephritis. Kidney Int 2005;68: 1086-1095.

15 Hartner A, Klanke B, Cordasic N, Amann K, Schmieder RE, Veelken R, Hilgers KF: Statin treatment reduces glomerular inflammation and podocyte damage in rat deoxycorticosterone-acetate-salt hypertension. J Hypertens 2009;27:376-385.

16 Amann K, Irzyniec T, Mall G, Ritz E: The effect of enalapril on glomerular growth and glomerular lesions after subtotal nephrectomy in the rat: a stereological analysis. J Hypertens 1993;11:969-975.

17 Amann K, Rump LC, Simonaviciene A, Oberhauser V, Wessels S, Orth SR, Gross ML, Koch A, Bielenberg GW, Van Kats JP, Ehmke H, Mall G, Ritz E: Effects of low dose sympathetic inhibition on glomerulosclerosis and albuminuria in subtotally nephrectomized rats. J Am Soc Nephrol 2000;11:1469-1478.

18 Schwarz U, Amann K, Orth SR, Simonaviciene A, Wessels S, Ritz E: Effect of $1,25(\mathrm{OH})_{2}$ vitamin $\mathrm{D}_{3}$ on glomerulosclerosis in subtotally nephrectomized rats. Kidney Int 1998;53:1696-1705.

19 Weibel ER: Stereological Methods, vol 1: Practical Methods for Biological Morphometry. London, Academic Press, 1979.

20 Dötsch J, Schoof E, Schocklmann HO, Brune B, Knerr I, Repp R, Rascher W: Nitric oxide increases adrenomedullin receptor function in rat mesangial cells. Kidney Int 2002;61: 1707-1713

21 Hartner A, Cordasic N, Klanke B, Muller U, Sterzel RB, Hilgers KF: The $\alpha 8$ integrin chain affords mechanical stability to the glomerular capillary tuft in hypertensive glomerular disease. Am J Pathol 2002;160:861867.

22 Hartner A, Porst M, Gauer S, Prols F, Veelken R, Hilgers KF: Glomerular osteopontin expression and macrophage infiltration in glomerulosclerosis of DOCA-salt rats. Am J Kidney Dis 2001;38:153-164.

23 Haas CS, Amann K, Schittny J, Blaser B, Muller U, Hartner A: Glomerular and renal vascular structural changes in $\alpha 8$ integrindeficient mice. J Am Soc Nephrol 2003;14: 2288-2296.

24 Knerr I, Dittrich K, Miller J, Kummer W, Rosch W, Weidner W, Rascher W: Alteration of neuronal and endothelial nitric oxide synthase and neuropeptide $\mathrm{Y}$ in congenital ureteropelvic junction obstruction. Urol Res 2001;29:134-140.

25 Bagchus WM, Hoedemaeker PJ, Rozing J, Bakker WW: Glomerulonephritis induced by monoclonal anti-Thy-1.1 antibodies. A sequential histological and ultrastructural study in the rat. Lab Invest 1986;55:680-687.

26 Gurani A, et al: Congenital nephron deficit (first hit) predicts increased renal injury in uninephretomized rats (second hit). Annual
Meeting of the American Society of $\mathrm{Ne}$ phrology, Toronto 2000, abstr 3268 .

27 Duncan RC, Bass PS, Garrett PJ, Dathan JR: Weight at birth and other factors influencing progression of idiopathic membranous nephropathy. Nephrol Dial Transplant 1994;9: 875.

28 Hellstrom M, Hessel H, Jacobsson B, Jodal U, Niklasson A, Wennerstrom M, Hellstrom A: Association between urinary tract infection, renal damage and birth size. Acta Paediatr 2001;90:628-631.

29 Rossing P, Tarnow L, Nielsen FS, Hansen BV, Brenner BM, Parving HH: Low birth weight. A risk factor for development of diabetic nephropathy? Diabetes 1995;44:1405-1407.

30 Nelson RG: Intrauterine determinants of diabetic kidney disease in disadvantaged populations. Kidney Int Suppl 2003:S13-S16.

31 Zimanyi MA, Denton KM, Forbes JM, Thallas-Bonke V, Thomas MC, Poon F, Black MJ: A developmental nephron deficit in rats is associated with increased susceptibility to a secondary renal injury due to advanced glycation end-products. Diabetologia 2006;49: 801-810.

32 Brenner BM, Garcia DL, Anderson S: Glomeruli and blood pressure. Less of one, more the other? Am J Hypertens 1988;1:335-347.

33 Schreuder M, Delemarre-van de Waal H, van Wijk A: Consequences of intrauterine growth restriction for the kidney. Kidney Blood Press Res 2006;29:108-125.

34 Schreuder MF, Nyengaard JR, Fodor M, van Wijk JA, Delemarre-van de Waal HA: Glomerular number and function are influenced by spontaneous and induced low birth weight in rats. J Am Soc Nephrol 2005;16: 2913-2919.

35 Wada Y, Morioka T, Oyanagi-Tanaka Y, Yao J, Suzuki Y, Gejyo F, Arakawa M, Oite T: Impairment of vascular regeneration precedes progressive glomerulosclerosis in anti-Thy-1 glomerulonephritis. Kidney Int 2002;61: 432-443.

36 Hughson M, Farris AB 3rd, Douglas-Denton R, Hoy WE, Bertram JF: Glomerular number and size in autopsy kidneys: the relationship to birth weight. Kidney Int 2003;63:21132122 .

37 Amann K, Plank C, Dötsch J: Low nephron number - a new cardiovascular risk factor in children? Pediatr Nephrol 2004;19:13191323 .

38 Kriz W, Gretz N, Lemley KV: Progression of glomerular diseases: is the podocyte the culprit? Kidney Int 1998;54:687-697.

39 Keller G, Zimmer G, Mall G, Ritz E, Amann K: Nephron number in patients with primary hypertension. N Engl J Med 2003;348:101108

40 Moritz KM, Mazzuca MQ, Siebel AL, Mibus A, Arena D, Tare M, Owens JA, Wlodek ME: Uteroplacental insufficiency causes a nephron deficit, modest renal insufficiency but no hypertension with ageing in female rats. J Physiol 2009;587:2635-2646. 